\title{
Quando nasce um bebê \\ O Pensamento Sensível e o Pensamento Simbólico no Teatro do Oprimido
}

\author{
Augusto Boal
}

\section{o Corpo e o Conhecimento}

uando nasce um bebê é um corpo humano que vem ao mundo. Passam a existir o corpo e o mundo - o corpo no mundo. Esse corpo não traz consigo nenhum preconceito, nenhum parti-pris, idéias inabaláveis, certezas ou intransigências. Não torce por nenhum time de futebol e não professa nenhuma religião. Não faz filosofia nem compara valores - desconhece valores: é apenas um corpo humano.

Não possui nenhum Conhecimento $a$ priori, no sentido kantiano ${ }^{1}$, que ultrapasse os limites do que lhe é orgânico e, nele, singular. Apenas traz consigo seus cinco sentidos, necessidades biológicas e, mais tarde, incipientes desejos. Sobretudo, traz um cérebro com cem bilhôes de neurônios que criam infinitas sinapses: a Mente, que é a sua vida psíquica, organizadora de emoçôes e produtora de idéias e projetos.

Seus sentidos já existiam, em desenvolvimento, dentro do ventre materno, e já guardavam memórias. Sua pele já tocava o líquido amniótico, que poucas variações tinha de temperatura e consistência. Seus ouvidos já recebiam sons vindos de fora, amortecidos; sua boca ape- nas sentia sabor nos lábios apertados; seus olhos nada viam, e seus pulmões não respiravam.

O nascimento produz um choque sensorial de tremenda violência, e o bebê chora. Assustado, pensa: pensa um pensamento mudo, pois não conhece palavras. Sua pele toca outras peles, roupas e coisas - ele sente e compara. Sons, à sua volta, tornam-se explosivos e diversificados. Pela primeira vez seus pulmões se repletam de ar e o bebê cheira. Saboreia o leite materno. Seus olhos, quando se abrem bem abertos, ao tudo verem, nada vêem: lentamente, ao longo dos dias que passam, das pessoas e coisas que passam, distinguem traços e cores, desenham perspectivas e reconhecem fisionomias.

Os primeiros contatos com o mundo exterior são de natureza sensorial - isto é, estéticos. A Estética nasce com o bebê.

\section{A Estética como Pensamento Sensível}

Quando, entre 1750 e 1758, o filósofo alemão Alexander Baumgarten escreveu seus dois livros sobre a Estética, ele a definiu assim: "Os Sentidos, - e os Conhecimentos que deles derivam - , permitem imaginar uma gnosiologia inferior.

Augusto Boal é dramaturgo, encenador e coordenador do Centro do Teatro do Oprimido.

1 Conhecimento que não depende e é anterior à experiência prática. 
Não duvido que possa existir uma Ciência do Conhecimento Sensível... intermediária entre a sensação pura, obscura e confusa, e o puro intelecto, claro e distinto. Ela não é nem algo existente na própria Coisa, nem pura criação do ser humano: é o resultado de uma síntese particular, harmonia entre Coisa e Pensamento. O Conceito Sensível é particular, como objeto de sensibilidade; e geral, como objeto de entendimento".

Estética é uma relação Sujeito-Objeto, concordo. Discordo apenas do uso da palavra "inferior" para designar o Conhecimento Sensível que não é uma função estática, arquivo morto ou mero registro de Informações sensoriais, mas sim o orquestrador das novas informações com as anteriormente recebidas, e com os desejos e necessidades do Sujeito.

Quero adotar a idéia de que existe uma outra forma de pensar, não verbal - o Pensamento Sensível -, que é dinâmico, articulado e resolutivo.

O fluxo contínuo de nossas ações e decisões, que levam em conta, e ao cabo, as informações orquestradas pelo Conhecimento, são obra de um verdadeiro Pensamento Sensível que, dinamizando esse Conhecimento, determina e orienta a dinâmica do Sujeito.

O Conhecimento Sensível organiza o Léxico de todos os elementos psíquicos em Sintaxe valorativa - conjuga-se no presente do indicativo; o Pensamento Sensível, apoiado no Conhecimento, é Gerúndio. O Conhecimento oferece opções; o Pensamento escolhe e inventa. O Conhecimento interroga; o Pensamento responde. O Conhecimento é o conhecido; o Pensamento, o conhecer. O Conhecimento traz o passado até o instante presente; o Pensamento, do instante, avança para o futuro. Ambos são etapas interpenetráveis de um mesmo processo psíquico.

Também não me parece adequada a expressão "puro intelecto" pois tal pureza não existe: o Intelecto é o resultado da metamorfose contínua e progressiva de sensações, emoções e idéias, atuais e passadas, que rodopiam na Mente, antes de se projetarem no futuro como fala e ação. Mas concordo que, na formação do Intelecto, existe um salto vital, impossível de ser conhecido: da mesma forma que o ácido desoxirribonucléico adquire vida, - ou nela se transforma, sem que saibamos como, nem porquê -, o cérebro orgânico cria a Mente multifária e, esta, o Intelecto refinado.

A Estética não é a Ciência do Belo, como se costuma dizer, mas sim a da Comunicação Sensorial e da Sensibilidade. Fosse somente a Ciência do Belo e do Sublime, teríamos que inventar uma outra palavra para designarmos o quase-Belo, o menos-Belo e a Fealdade. O Belo, que da Estética faz parte, é a organização sensorial da realidade, anárquica e aleatória, em formas que lhe dão sentido e, a nós, prazer. Pode ser traduzido e explicado em palavras, mas não as necessita.

O Feio, que é o antônimo apenas de Bonito, pode ser Belo. O Feio é Belo - não há nisto nenhuma contradição. Bela é a Verdade. Qual? Como não somos todos iguais, haverá muitas. A Estética não tem valores universais.

Afirmo também que não existe o MaisBelo e o Menos-Belo, conceitos criados em sociedades individualistas, capitalistas e neoliberais, em que é importante ser sempre o primeiro, o melhor. Penso, ao contrário, que cada Coisa é ou não Bela em função da sua capacidade de, através dos nossos sentidos, significar uma verdade real ou imaginária, dentro de condições temporais e concretas, quer nos atraia ou assuste.

O Maria Fumaça e o Trem-Bala, o carrinho de mão e o carro de corridas, são belos em suas realidades sociais, como, nas naturais, o arbusto e a sequóia, o riacho e o mar.

\section{O Corpo e o Mundo}

Para sobreviver, o bebê precisa conhecer o mundo - sobretudo, o seu lugar no mundo. No entanto, os estímulos que recebe são pletóricos e confusos, desordenados, difíceis de entender. Seus sentidos registram sensações torrenciais. 
Aquelas que se repetem são fixadas no seu cérebro e, organizados por sua mente, servirão de parâmetros e paradigmas para receber e estruturar as próximas que virão.

Sensações não nos vêm isoladas, puras e refratárias: cada uma recebe e produz emoções específicas. Se o bebê mama, o estômago saciado e o sabor do leite se associam ao prazer de tocar o corpo da mãe, sentir seu cheiro, ouvir sua voz. Cada sensação está envolta em emoçôes e memórias.

Se o bebê ouve música suave, se reconforta; ouvindo techno, essa agressiva sensação virá associada ao espanto e à dor. Sendo confrontado à luz de holofotes, seu corpo se retrai em sofrimento e se pacifica, se exposto à suave luz azul.

Progressivamente, sensações e emoções, e as memórias a elas referentes -, são organizadas pelo Conhecimento em estruturas sensoriais, mnemônicas e emotivas que, em movimento, são o Pensamento Sensível. Nele, e entre elas, existe o fenômeno da Sinestesia que propicia o seu entrelaçamento e interdependência. ${ }^{2}$

O bebê passa a pressentir, sinestesicamente, aqueles estímulos que prenunciam prazeres, - como a mãe que se aproxima para lhe dar de mamar -, ou ameaçam dores: vozes distantes ou gritos.

Suas faculdades motoras se desenvolvem; nessa medida, o bebê aprende que, não só é capaz de perceber o mundo, mas é também capaz de se associar a ele. Ouve música e move o corpo, dança, perseguindo o ritmo que nem sempre encontra. Reage, com prazer, ao canto dos pássaros, e teme o trovão. Sente o cheiro de leite e busca o seio. Vê o pai ou a mãe, e abre os braços. Aprende a sorrir - grande invenção humana.

Quanto mais se desenvolvem seus músculos, mais aprende que pode, não apenas perceber e se associar ao mundo, mas pode também transformá-lo. Se levarmos uma criança à praia, com areia ela fará uma escultura e se descobrirá escultora. Se lhe dermos papel branco e lápis de cor, ela se descobrirá pintora. Se lhe dermos peças de armar, fará uma bela arquitetura - a criança é arquiteta.

Nesta seqüência - perceber o mundo, associar-se a ele e transformá-lo - estes são os primeiros contatos da criança com o mundo que a cerca: contatos estéticos, artísticos, organizadores de sensações, às quais atribui valores e qualidades. Essa forma de pensar e de se relacionar com o mundo é uma forma estética de conhecê-lo e, com ele, dialogar. As linguagens estéticas são cognitivas - são, em si mesmas, Conhecimento.

\section{A Palavra e o Pensamento Simbólico}

O bebê, desde cedo, começa a reter em sua memória sons seqüenciais associados continuamente às mesmas coisas e pessoas, atos ou fatos, presentes ou futuros: são as Palavras. Surge o Pensamento Simbólico.

A soberana Palavra nos traz o Conhecimento Abstrato que é produzido pelas linguagens informativas: ${ }^{3}$ aquelas que transportam

2 Sinestesia é o diálogo entre os sentidos, p. ex., a visão de uma pessoa ou coisa que provoca sensações epidérmicas de prazer ou dor, emoções de medo ou atração. Diferente da Cenestesia que se refere às impressōes sensoriais internas do organismo que nos fazem sentir bem-dispostos ou tensos, saudáveis ou doentes.

3 Se uma pessoa a outra diz - "Eu te amo" -, essa frase refere-se ao amor, mas não é o amor. Se nada disser, e apenas olhar a pessoa amada, seu olhar é o amor. A palavra amor é linguagem informativa, enquanto que a voz com que é pronunciada, e o rosto de quem a pronuncia naquele momento, esses, são linguagem cognitiva. 
Conhecimento, mas não são Conhecimento; referem-se à Coisa, mas não são a Coisa. São simbólicas e não sinaléticas. ${ }^{4}$

A Linguagem das Palavras é essencial na constituição do Ser Humano, pois permite articular pensamentos sobre o que não está em contato direto com os sentidos, pensar o Futuro que não existe, refletir sobre o passado revoluto; permite adiar e antecipar, organizar o tempo e dar significados ao espaço, fazer promessas e ameaças, jogar xadrez, criar agendas, usar o dinheiro e o cartão de crédito, emprestar e cobrar juros, fazer hipotecas e continuar morando na mesma casa, imaginar o não-acontecido e ponderar possibilidades de acontecer.

Com a invenção da Palavra, o Ser Humano descobriu também a Mentira e suas formas mais comuns: o Falso-Testemunho e a Calúnia, eficazes armas de Poder. Com a Mentira surgiu a Hipocrisia que é a possibilidade de se dar contínua aparência de verdade ao que o Sujeito sabe ser falso. O Pensamento Simbólico sufoca o Pensamento Sensível.

Criando uma outra forma de vida, a Palavra torna mais complexa e densa a Realidade, e a boa relação entre os dois Pensamentos pode entrar em franca colisão.

É curioso lembrar que a palavra grega Hupokrisia, entre os seus vários sentidos, tinha o de "Desempenhar um papel em uma peça" isto é: a Arte do Ator. Significava também: "A resposta do Oráculo”. Oráculo e Ator, ambos misteriosos, tinham, e conservam, o mágico poder de impor empática submissão aos seus interlocutores e, neles, inocular mensagens, sentimentos e valores. A Empatia é arma perigosa, instrumento de convencimento e poder.
A Ficção, que é uma variante da Mentira criada e transmitida através da Empatia, revelase como uma outra forma, - paralela, estruturada e coerente -, de compreensão ou interpretação do real que pode produzir opressivas e categoriais estruturas de raça, casta ou classe, credo ou sexo. Torna-se uma outra Realidade, onde até mesmo o Improvável e o Impossível passam a ser categorias do Real.

A palavra Ficção torna-se a única ficção que realmente existe, pois que existe descolada de qualquer realidade.

A luta pela posse do Território, tão comum entre os animais predatórios como nós, os humanos, estendeu-se às palavras e não somente à terra e aos bens materiais.

Liberdade e Democracia, por exemplo, passaram a ter o significado que lhes atribuem os seus proprietários, e perderam o sentido etimológico que possuíam ao serem criadas. $\mathrm{O}$ neoliberalismo chama de demo-cracia (o poder do povo) ao que todos sabemos ser uma plutocracia (o poder do dinheiro), e Liberdade passa a designar a razão do mais forte.

Com a introdução da Palavra, que é simbólica, as linguagens estéticas, que são sinaléticas, esmaecem e se tornam cada vez menos conscientes e consistentes. O Pensamento Sensível torna-se diáfano ou obscuro: não vemos com nitidez o que olhamos, não escutamos com precisão o que ouvimos, nem sentimos em toda sua extensão o que tocamos. Prestamos atenção ao significado das palavras - mas não ao timbre, volume, ritmo e outras características sensoriais da voz. Definha, em nós, o artista. ${ }^{5}$

No entanto, o corpo humano e as linguagens estéticas são capazes de um Conheci-

4 Nas linguagens simbólicas os significantes estão dissociados do significado; nas linguagens sinaléticas, significantes e significados são inseparáveis. No exemplo anterior, a palavra amor é simbólica e o rosto do amante sinalético.

5 Temos que re-aprender a ver a coisa no espaço, o espaço da coisa, e o espaço do espaço, feito coisa; temos que sentir o que toca o nosso corpo, e sentir o corpo; escutar os sons que ouvimos, e os que estáo gravados na memória. Temos que redescobrir o corpo: temos um corpo. 
mento, paralelo e simultâneo ao das palavras, indispensável para a mais ampla e multidimensional percepção do mundo, e para a sua compreensão mais profunda. São formas de conhecer que produzem um Conhecimento específico que somente através delas se obtém, e às outras se acrescenta. O que aprendemos ao ver uma pessoa, é insubstituível pelo que, dela, possam nos dizer. Ouvi-la nos traz um conhecimento que é insubstituível pelo que, da sua voz, se possa predicar.

Esse Conhecimento e esse Pensamento Sensíveis ${ }^{6}$ podem ser traduzidos em palavras linguagem simbólica, - porém, ao serem traduzidos em Pensamento Simbólico, perdem a sua essência, como acontece quando alguém explica um quadro ou uma sonata. A sonata e o quadro já falavam por si, e a palavra, embora traga outra forma de Conhecimento, obscurece momentaneamente a percepção estética.

O Pensamento Sensível, veloz e incessante, é base e raiz do Pensamento Simbólico, intermitente e lento, sem o qual este não existiria, mas que existe sem aquele. Não necessita se transformar em Pensamento Simbólico, isto é, em palavras, porque são dois diferentes níveis e formas de pensar.

O Pensamento Sensível, primogênito e genitor, inventa as Palavras, e as Palavras, organizadas, constroem o Pensamento Simbólico.

Os dois Pensamentos, o Sensível e o Simbólico, interagem, subdividem-se e multiplicam-se, amalgamam-se impuros, e variam seus fluxos a cada instante. Despertos, podem se assumir como Consciência, que consiste em pensar o pensamento, criticamente, como Sujeito que examina o seu Objeto: avalio o que penso, pensando em vários níveis simultâneos, e deci- do o que faço. A Consciência é Ética: escolhe seus valores... sejam quais forem.

O Pensamento Sensível não ocupa nenhum espaço no tempo, mas o Pensamento Simbólico exige tempo para ocupar o seu espaço.

Esse é o segredo da Arte.

O Teatro do Oprimido, - como Arte que é -, sem desvalorizar a Palavra, procura estimular nos seus participantes, através dos sentidos, o Conhecimento e o Pensamento Sensíveis em cada instante da Ação teatral, metáfora da vida, em cada Imagem e em cada Som. Vai além, e procura conhecer a própria Palavra como objeto sensível, pois entende que toda Sintaxe é Poesia - pode ser ruim, mas é poesia...

Duas palavras, quando se associam, criam um terceiro Ser, soma infinita de significados. ${ }^{7}$

O Pensamento Sensível encara o Pensamento Simbólico: entre os dois, sobrevém a cordialidade complementar... ou a pororoca lingüística e sensorial se estabelece.

Sendo imperfeitos nossos sentidos, - únicos em cada ser humano -, cada um de nós terá, desse mundo, uma percepção imperfeita e única.

Apesar disso, podemos dizer que nossas percepções do mundo, - embora sejam apenas $o$ nosso mundo e não $o$ mundo -, assemelham-se entre elas e, dele, podemos predicar algumas características reconhecidas por todos, cada qual a seu modo que, embora diferente, é semelhante: isto é uma cadeira; aquilo, uma mesa; este, um oprimido; aquele, um opressor.

Temos que reconhecer, no entanto, que nossa singular visão da mesa e da cadeira, como de tudo que nos cerca, tem os limites da nossa percepção, envolta, como está, em nossas emoções e memórias; articulada, como está, com nossos desejos e necessidades.

6 O Conhecimento é o articulador das informaçōes, e o Pensamento é o formador de decisões e o provedor de açôes que passam, ou não, pela Consciência.

7 Chove indica água que cai do céu; muito, indica uma quantidade indefinida. Chove muito, designa desde a fina garoa até a torrencial tempestade tropical. 
O Teatro do Oprimido, ao propor os cidadãos como atores e espectadores, - espect-atores - palco e platéia, Objetos e Sujeitos da ação dramática e do diálogo-fórum, deve, necessariamente, começar pelo relato individual de uma história verdadeira: uma opressão particular - o Coro é formado por indivíduos.

A partir do particular, no entanto, não se dirige à singularidade dessa opressão, mas sim à generalidade de opressões semelhantes - do indivíduo ao grupo social.

Essa expansão, ao mesmo tempo em que se espraia pelo múltiplo, aprofunda-se na unicidade de cada participante, pois a vida social penetra e se reflete na mente de cada cidadão: não é possível separar, estanques, o mundo lá de fora e o de dentro de nós - a assim chamada política, e a psicologia, assim chamada.

Vivemos flutuando no real, sem com ele nos confundirmos. Como nossas particulares flutuaçôes se assemelham, podemos dialogar Diálogo Social codificado, cheio de imperfeições e mal-entendidos, mas baseado no tácito acordo de que estamos falando da mesma coisa quando sabemos, conscientes ou não, que falamos de coisas diferentes.

Esse Diálogo Social é por todos aceito em função da relação custo-benefício: ao preço de fingimento e faz-de-conta, renunciamos à busca do inaccessível Conhecimento do Outro para ganharmos a agradável sensação de sermos parceiros, até iguais. Incluímos ainda, na coluna dos ganhos, a possibilidade otimista de nos aproximarmos, cada vez mais, de um quase-conhecimento através desse quase-diálogo, e chegarmos a uma quase-verdade.

\section{Delírio, alucinação \\ e as formas delirantes da Arte}

Essa flutuação sobre o real encontra, em condições e momentos especiais, a feição de decolagens e vôos siderais.

Quando um poeta, imerso em seus pensamentos, memórias e imaginações, escreve o seu poema; quando um pintor, alheio ao mundo, pinta o seu quadro; quando um compositor escuta sons que transcreve em partituras, sem que ninguém os ouça; quando o ator sobe ao palco e finge ser quem ele sabe que não é, e os espectadores fingem acreditar, e acreditam estes são casos de Formas Delirantes de percepção estética do mundo.

Formas Delirantes diferem dos Delírios porque são socialmente enquadradas, ritualizadas, estruturadas, - têm lugar, modo e hora -, e porque são, ou podem ser, reversíveis pelo próprio sujeito que as produz.

No Delírio Patológico, o sujeito, por si só não é capaz, ou é pouco capaz, de fazer esta reversão; incapaz mesmo de compreendê-la e de compreender-se.

Formas Delirantes são ainda diferentes porque os Delírios são repetitivos, limitados a poucas interpretações do real, empobrecedores, enquanto que as Formas Delirantes são criativas, imaginosas, e rompem limites.

Por essa virtude de romper limites, as Formas Delirantes correm o risco de se transformarem em Alucinações ${ }^{8}$, o que ocorre quando são ativadas sensaçôes sem os objetos que as provoquem, quando se pode ver o que não existe e pode-se abraçar a imaginação. Isto acontece nos

8 O Delírio interpreta erroneamente a realidade que existe, atribuindo-lhe valores e propósitos que, reconhecidamente, não são verdadeiros, ou não se coadunam com a usual interpretação coletiva; a Alucinação cria uma realidade inexistente através de sensações, imagens e sons que, igualmente, inexistem.

O Delírio pode ser uma forma de racionalizar a Alucinação, que pode ter sido o seu estágio anterior, mas pode, igualmente, provocá-la: Alucinógeno produto da Alucinação.

As Formas Delirantes afastam-se da realidade objetiva, que é por todos compartida, e instalam-se em uma realidade criada, para a qual a todos convida (como no teatro, conserto musical ou dança), ou das quais a todos exclui (como no momento criativo solitário do pintor ou compositor). 
transes alucinados de certas religiões animistas, como nos transes alucinados de certos pintores, compositores, atores e outros artistas.

Formas Delirantes e Alucinações, são maneiras especiais com as quais o Sujeito organiza e estrutura, valora e expressa, a sua percepção do mundo - nisso se assemelham. São diferentes porque, na Alucinação, o Sujeito torna-se vítima do descontrole perceptivo e, nas Formas Delirantes, o Sujeito se permite e atinge os limites desse descontrole, sem ultrapassá-lo.

Assemelham-se, ainda, porque ambas são aventuras investigatórias do intelecto, governado ou não.

Podemos mesmo falar de uma Alucinação Estética, controlável pelo artista, diferente da Alucinação Patológica, senhora do paciente.

\section{Teatro do Oprimido - Arte e Política}

Vivemos uma época que não é melhor nem pior do que outras - é igualmente cruel, individualista e excludente.

Olhando para o passado, vemos desumanas guerras religiosas e pagãs, etnocídios e variadas formas de genocídios. Isto é o mesmo que hoje vemos, não só nos bárbaros países africanos e asiáticos, mas nos civilizados europeus e americanos: mata-se à tripa forra.

Se, ontem, piratas e flibusteiros atacavam e roubavam as naus em alto-mar, hoje bandidos e meliantes assaltam carros e ônibus na Linha Vermelha, caminhões na estrada.

Se, ontem, soldados marchavam a pé cruzando fronteiras contíguas, hoje, exércitos inteiros viajam de continente a continente, e matam, - não espada na mão, mas suavemente teclando sofisticados computadores que, à distância, disparam bombas inteligentes e impiedosas que sobrevoam países e perseguem seus inimigos com raios infravermelhos e ultravioletas, lazer, e o que mais se invente.

Concordo com Shakespeare para quem o teatro é Arte que nos mostra a nossa verdadeira cara - virtudes e vícios. Isto é a nossa Arte. Mas não concordo que isso baste: se não nos agrada nossa cara, há que mudá-la.

Temos que invadir esse espelho e, como faz a criança com a areia da praia, temos que fazer a escultura de como queremos ser.

Arte é Política. Teatro é movimento: mostra ações humanas, atos sociais, e todas ações humanas têm sentido, meta e significado. Por que parar quando baixa o pano? Aí começa!

Concordo com aqueles filósofos que disseram, como Hegel, que a "Arte é o luzir da Verdade através dos meios sensoriais". Mas não concordo que essa verdade que luz, se olharmos cara a cara o mundo em que vivemos, seja divina como pensava o filósofo: é terrena.

Nem sempre é bela, mas bela há que torná-la. Como faz a criança pintando suas cores.

Concordo que temos que buscar a Verdade, aquela que mostre porque a dor existe, e quem a causa. Mas não nos basta a Imagem do Espelho: temos que inventar outra Imagem que nos satisfaça, - imagem sem opressão -, e persegui-la.

Como faz a criança quando aprende a dizer "Não!"

Teatro é arte dinâmica: não podemos paralisá-la dizendo - "Assim é a vida!" - antes digamos: "Assim será!"

Embora sejam fundamentais e insubstituíveis - por isso escrevo! - não será só com palavras que conheceremos o mundo; menos ainda poderemos transformá-lo. No teatro, ensaia-se para o espetáculo e, no espetáculo, fisicamente e não só com palavras, devemos ensaiar os meios de transformar o mundo: entrando em cena. Depois, no real, temos que transformá-lo.

Ensaiar com os sentidos, as emoçóes, a inteligência e a criatividade que tínhamos como crianças, mas com a experiência vivida, a coragem e a responsabilidade que temos agora, como adultos.

Ensaiar e, depois, extrapolar para a sociedade o que descobrirmos no palco ou na arena.

$\mathrm{O}$ jogo da criança era à brinca; o nosso, é à vera. 